\title{
ANÁLISE DA ARBORIZAÇÃO DO CAMPUS SEDE DA UNIVERSIDADE FEDERAL RURAL DO SEMI-ÁRIDO, MOSSORÓ-RN
}

\author{
ANALYSIS OF THE AFFORESTATION OF THE MAIN CAMPUS HEADQUARTERS \\ OF THE FEDERAL RURAL UNIVERSITY OF SEMI-ARID, MOSSORÓ-RN
}

\author{
Francisco Edislan Gurgel Diógenes ${ }^{1}$, Tallyta Martins de Sousa², Rejane Tavares Botrel ${ }^{3}$, \\ Vinicius Gomes de Castro ${ }^{4}$
}

\begin{abstract}
RESUMO
A arborização urbana deve seguir um planejamento prévio de execução, levando em consideração características da região na escolha adequada das espécies a serem implantadas. O objetivo deste trabalho foi analisar os indivíduos arbóreos, de diferentes idades e portes, do Campus Sede da Universidade Federal Rural do Semi-Árido, em Mossoró-RN. A análise foi realizada por meio de amostragem da vegetação arbórea das calçadas e estacionamentos das principais vias do campus. Foram coletados dados gerais quanto à localização e identificação das espécies, informações dendrométricas e biológicas, como também, o levantamento de dados quanto ao entorno e interferências às árvores. Foram registrados 527 indivíduos arbóreos, distribuídos em 18 famílias botânicas e 38 espécies. Foi observada uma predominância de um pequeno grupo de determinadas espécies em relação às outras, como também a predominância de indivíduos de espécies de origem exótica. Buscando a proteção e conservação do rico Bioma das Caatingas, seria necessário realizar um planejamento de rearborização do Campus, dando preferência à implantação de árvores de espécies nativas, minimizando os possíveis impactos negativos causados pela alteração da vegetação local.
\end{abstract}

Palavras-chave: Caatinga; Diversidade vegetal; Campus universitário.

\section{ABSTRACT}

The urban afforestation should follow a previous planning of execution, taking into account characteristics of the region in the appropriate choice of species to be implanted. The objective of this study was to analyze the arboreal individuals, of different ages and sizes, of the main Campus of the Federal Rural University of Semi-Arid, in Mossoró-RN. The analysis was carried out by the arboreal vegetation's sampling means of the sidewalks and parking lots of the main roads of the campus. General data were collected regarding the location and identification of species, dendrometric and biological information, as well as data collection regarding the environment and interference to trees. There were found 527 arboreal individuals, distributed into 18 botanical families and 38 species. It was observed a predominance of a small group of certain species in relation to the others, as well as the predominance of individuals of exotic origin species. Seeking the protection and conservation of the rich Biome of Caatingas, it would be necessary to carry out a reforestation planning of the Campus, giving preference to the implantation of native species trees, minimizing the possible negative impacts caused by the alteration of the local vegetation.

Keywords: Caatinga; Plant diversity; University campus.

Recebido em 14.03.2018 e aceito em 16.01.2019

1 Graduando em Engenharia Florestal pela Universidade Federal Rural do Semi-Árdio - UFERSA. Mossoró/RN. Email: edislandiogenes@hotmail.com

2 Graduanda em Engenharia Florestal pela UFERSA. Mossoró/RN. Email: tallytamartins1@gmail.com

3 Engenheira Florestal, Profä. Dra. do Centro de Ciências Agrárias da UFERSA. Mossoró/RN. Email: rtbotrel@ufersa.edu.br

4 Engenheiro Florestal, Profón. Dr. do Centro de Ciências Agrárias da UFERSA. Mossoró/RN. Email: vinicius.castro@ufersa.edu.br 


\section{INTRODUÇÃO}

O Rio Grande do Norte é um dos estados que compõem a região Nordeste do Brasil e está inserido na Caatinga, o único bioma exclusivamente brasileiro. Este bioma é composto por uma grande diversidade de plantas arbóreas, arbustivas e herbáceas, que compartilham de características como a adaptação à deficiência hídrica e ao clima semiárido, abrangendo uma área de aproximadamente $734 \mathrm{mil} \mathrm{km}^{2}$ (GARIGLIO, 2010).

A observância do bioma da região é importante para a implantação da arborização urbana, pois esta deve seguir um planejamento que envolve a seleção das espécies mais adequadas para o plantio paisagístico. Esta escolha deve levar em consideração diversos aspectos, como o ritmo de crescimento das árvores, as exigências específicas (como clima, solo e umidade), tipo de copa desenvolvida, porte das árvores, folhagem, entre outros. Assim o efeito da arborização é extremamente dependente da escolha da espécie e de como as árvores serão agrupadas (PAIVA; VITAL, 2003). Uma arborização não planejada ou realizada por pessoal incapacitado pode proporcionar efeitos negativos diretos ou indiretos ao seu meio, como interferências nas redes elétricas e de telefone, água, esgoto, dentre outros (REDIN et al., 2010).

Para que seja possível conhecer e realizar interferências na arborização urbana, seja na implantação ou manutenção, é necessária a realização de um inventário da arborização, que consiste em conhecer o patrimônio arbustivo e arbóreo de uma determinada localidade. Os dados obtidos por este inventário podem ser aplicados em processos de tomada de decisão sobre de intervenção aos indivíduos, seja através de poda, tratamentos fitossanitários, desbaste ou replantio (ROCHA; LELES; OLIVEIRA NETO, 2004).

Para o clima semiárido, característico da região nordeste, existe a indicação de algumas espécies arbóreas nativas e, também, exóticas que podem ser utilizadas em projetos paisagísticos. Porém, deve-se dar preferência para as espécies nativas, buscando minimizar os impactos na modificação da biodiversidade local (ALVAREZ; KILL, 2014).

Algumas espécies nativas que apresentam alto potencial para o plantio são: aroeira-dosertão (Myracrodruon urundeuva Allemão), angico-branco (Anadenanthera colubrina (Vell.) Brenan), angico-vermelho (Parapiptadenia rigida (Benth.) Brenan), pau-branco (Auxemma oncocalyx (Allemão) Baill), juazeiro (Ziziphus joazeiro Mart.), jurema (Mimosa spp.), marmeleiro (Croton hemiargyreus Müll. Arg.), mororó (Bauhinia fortificata L.), sabiá (Mimosa caesalpinaefolia Benth.), amburana (Amburana cearenses A. C. Smith), umbuzeiro (Spondias tuberosa L.), dentre outros exemplos (PAIVA; VITAL, 2003).

Contudo, nem sempre há um planejamento prévio e por isso torna-se importante realizar análises das condições dos indivíduos que compõe a arborização já implantada em ambientes urbanos. Esta análise deve ser quantitativa e qualitativa, indicando o sucesso ou fracasso 
relacionado às espécies arbóreas implantadas, possibilitando a adoção de estratégias para a resolução de problemas detectados. Sendo assim, o objetivo deste trabalho foi analisar, quanto aos dados dendrométricos, biológicos e de entorno e interferências, a arborização do Campus Sede da Universidade Federal Rural do Semi-Árido em Mossoró-RN.

\section{MATERIAL E MÉTODOS}

\section{Caracterização da área de estudo}

O trabalho foi desenvolvido no Campus Sede da Universidade Federal Rural do SemiÁrido - UFERSA, em Mossoró, no estado do Rio Grande Norte. O Campus, localizado na zona urbana da cidade de Mossoró, possui uma área territorial de aproximadamente $500.000 \mathrm{~m}^{2}$, sob as coordenadas geográficas: latitude $5^{\circ} 12^{\prime} 48^{\prime \prime} \mathrm{S}$, longitude $37^{\circ} 18^{\prime} 44^{\prime \prime} \mathrm{W}$ e altitude de $37 \mathrm{~m}$ acima do nível do mar (SILVA, 2014). A UFERSA é cortada pela rodovia federal BR110 que divide o campus em Leste e Oeste (Figura 1).

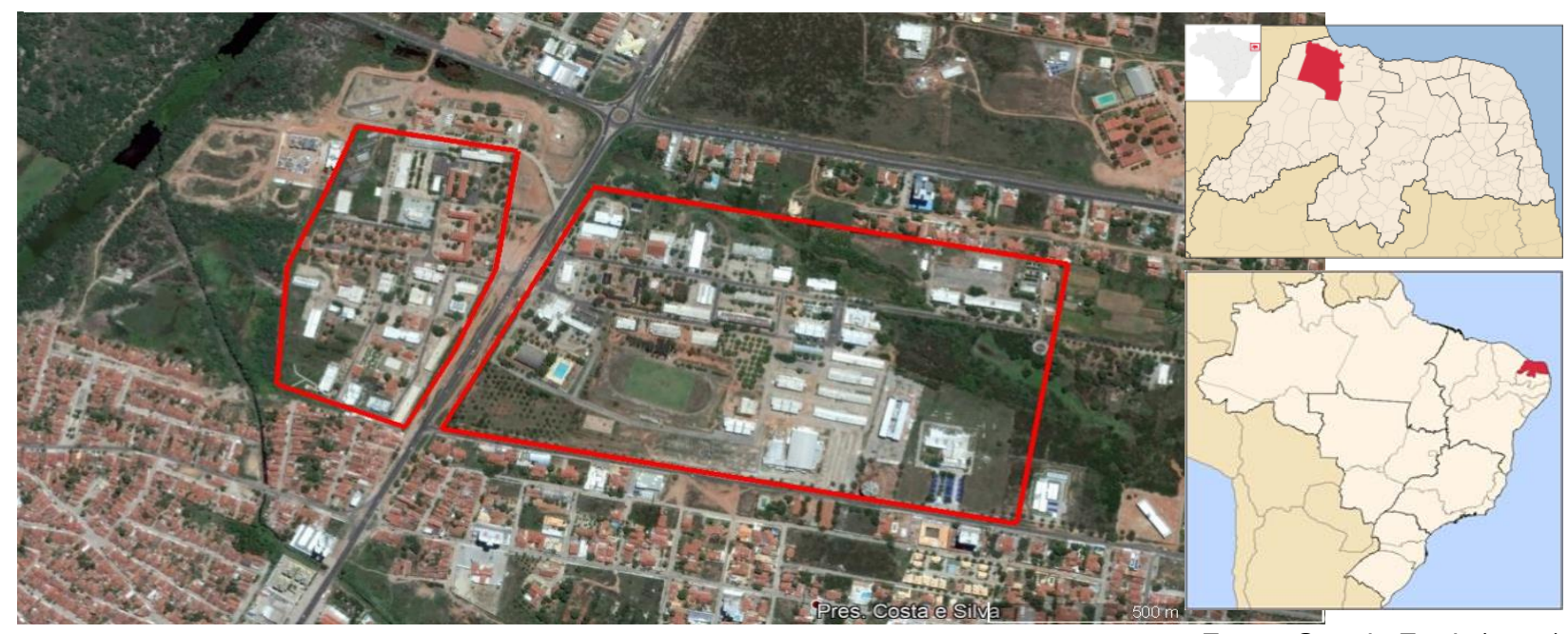

Fonte: Google Earth (2018)

Figura 1. Área do Campus Sede da Universidade Federal Rural do Semi-Árido - UFERSA, em MossoróRN (Campus Oeste à esquerda da rodovia e Campus Leste à direita)

Figure 1. Main campus area headquarters of the Federal Rural University of Semi-Arid - UFERSA, in Mossoró-RN (West campus to the left of the highway and east campus to the right)

Segundo Köppen, a classificação climática de Mossoró-RN é do tipo BSwh', seco e muito quente, com temperatura média anual de $28^{\circ} \mathrm{C}$ e índice pluviométrico médio de 788

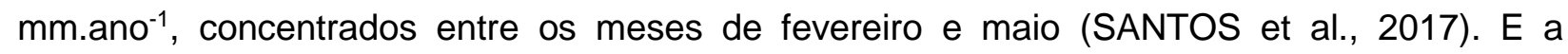
vegetação caracterizada por Caatinga hiperxerófila, carnaubal e vegetação halófita (DIAS; DIODATO; GRIGIO, 2014). 


\section{Processo metodológico}

Foi analisada uma amostra de 527 indivíduos arbóreos e arbustivos, de diferentes espécies, portes e idades, dispostos nas calçadas e estacionamentos ao longo das duas avenidas de maior fluxo de pessoas dentro da universidade, tanto no lado Leste (429 indivíduos), como no lado Oeste (98 indivíduos).

Inicialmente, foram medidas a largura das vias e calçadas nas principais ruas do campus. Posteriormente, foram feitas as análises da arborização, sendo esta dividida em quatro partes: localização e identificação das árvores; dados dendrométricos; dados biológicos; e entorno e interferências.

- Localização e Identificação: abrangendo informações quanto à data de coleta, número do indivíduo, nomes científico e comum, localização geográfica - utilizando como auxílio o GPS, e localização física (calçada, estacionamento ou adjacências). Ainda nesta etapa, as espécies eram classificadas quanto a sua origem, podendo ser nativas do Brasil ou exóticas;

- Dados Dendrométricos: abrangendo informações quanto à altura total, circunferência a 50 $\mathrm{cm}$ de altura do solo (definida a esta altura em consideração às características das espécies da região, como a tortuosidade e bifurcação precoce), diâmetro da copa (área da copa), porte (pequeno: até $5 \mathrm{~m}$; médio: entre 5 e $10 \mathrm{~m}$; e grande: acima de $10 \mathrm{~m}$ ) e idade (muda ou recém-plantada; árvore jovem; e árvore adulta) de cada indivíduo;

- Dados biológicos: abrangendo informações quanto ao estado geral, verificação das condições do sistema radicular, presença de injurias, fitossanidade, ecologia e fenologia de cada indivíduo;

- Entorno e interferências: abrangendo informações quanto à localização relativa, área livre de solo exposto, poda das árvores e rede elétrica.

As análises e observações feitas em campo foram coletadas e armazenadas com o auxílio de uma planilha manual de dados, adaptada de Silva Filho et al. (2002), e, posteriormente, os dados foram tabulados com o auxílio do Excel.

\section{RESULTADOS E DISCUSSÃO}

Através dos dados coletados foi possível inferir sobre diversas características quanto à arborização do Campus. Os 527 indivíduos arbóreos e arbustivos analisados foram classificados em 38 espécies diferentes (Tabela 1), sendo elas agrupadas em nativas ou exóticas. 
Tabela 1. Espécies arbóreas encontradas na análise da arborização urbana do Campus Sede da UFERSA, Mossoró-RN

Table 1. Tree species found in the urban afforestation analysis of the main campus of UFERSA, Mossoró-RN

\begin{tabular}{|c|c|c|c|c|}
\hline Nome Científico & Família & Nome Vulgar & Origem & Quant. \\
\hline Malpighia glabra L. & Malpighiaceae & Aceroleira & Exótica & 8 \\
\hline Hibiscus pernambucensis Arruda & Malvaceae & Algodão-do-Pará & Nativa & 1 \\
\hline Anadenanthera colubrina (Vell.) Brenan & Fabaceae & Angico & Nativa & 1 \\
\hline Myracrodruon urundeuva Allemão & Anacardiaceae & Aroeira & Nativa & 3 \\
\hline Syzygium cumini (L.) Skeels & Myrtaceae & Azeitona-roxa & Exótica & 3 \\
\hline Schinopsis brasiliensis Engl. & Anacardiaceae & Baraúna & Nativa & 6 \\
\hline Spondias lutea L. & Anacardiaceae & Cajarana & Nativa & 3 \\
\hline Anacardium occidentale L. & Anacardiaceae & Cajueiro & Nativa & 5 \\
\hline $\begin{array}{l}\text { Terminalia brasiliensis (Cambess. ex A. } \\
\text { St.-Hil.) Eichler }\end{array}$ & Combretaceae & Castanholeira & Exótica & 4 \\
\hline Poincianella bracteosa (Tul.) L.P. Queiroz & Fabaceae & Catingueira & Nativa & 5 \\
\hline Cassia fistula $\mathrm{L}$. & Fabaceae & Chuva-de-ouro & Exótica & 5 \\
\hline $\begin{array}{l}\text { Orbignya speciosa (Mart. ex Spreng.) Barb. } \\
\text { Rodr. }\end{array}$ & Arecaceae & Coco Babaçu & Exótica & 1 \\
\hline $\begin{array}{l}\text { Tabebuia aurea (Silva Manso) Benth. \& } \\
\text { Hook. f. ex S. Moore }\end{array}$ & Bignoniaceae & Craibeira & Nativa & 57 \\
\hline Albizia sp. & Fabaceae & Esponja & Exótica & 13 \\
\hline Cnidoscolus quercifolius Pohl & Euphorbiaceae & Faveleira & Nativa & 1 \\
\hline Cynophalla flexuosa (L.) J. Presl & Capparaceae & Feijão-bravo & Exótica & 1 \\
\hline Ficus benjamina L. & Moraceae & Ficus & Exótica & 1 \\
\hline Delonix regia (Bojer ex Hook.) Raf. & Fabaceae & Flamboyant & Exótica & 3 \\
\hline Gliricidia sepium (Jacq.) Kunth ex Griseb. & Fabaceae & Gliricidea & Exótica & 1 \\
\hline Inga sp. & Fabaceae & Ingá & Nativa & 6 \\
\hline Tabebuia sp. & Bignoniaceae & Ipê & Nativa & 45 \\
\hline Syagrus romanzoffiana (Cham.) Glassmar & Arecaceae & Jerivá & Exótica & 1 \\
\hline Ziziphus joazeiro Mart. & Rhamnacea & Juazeiro & Nativa & 3 \\
\hline Libidibia ferrea (Mart.) L.P. Queiroz & Fabaceae & Jucá & Nativa & 27 \\
\hline Leucaena leucocephala (Lam.) de Wit & Fabaceae & Leucena & Exótica & 2 \\
\hline Mangifera indica $\mathrm{L}$. & Anacardiaceae & Mangueira & Exótica & 42 \\
\hline Bauhinia variegata $\mathrm{L}$. & Fabaceae & Mororó & Nativa & 2 \\
\hline Erythrina mulungu Mart. ex Benth. & Fabaceae & Mulungu & Nativa & 5 \\
\hline Azadirachta indica A. Juss. & Meliaceae & $\mathrm{Nim}$ & Exótica & 134 \\
\hline Morinda citrifolia L. & Rubiaceae & Noni & Exótica & 15 \\
\hline Licania tomentosa (Benth.) Fritsch & Chrysobalanaceae & Oiti & Nativa & 26 \\
\hline Licania rigida Benth. & Chrysobalanaceae & Oiticica & Nativa & 1 \\
\hline Não identificada & Arecaceae & Palmeira & Exótica & 34 \\
\hline Eugenia uniflora L. & Myrtaceae & Pitanga & Exótica & 3 \\
\hline Spondias purpurea L. & Anacardiaceae & Siriguela & Nativa & 1 \\
\hline Phoenix dactylifera L. & Arecaceae & Tamareira & Exótica & 3 \\
\hline Tamarindus indica $\mathrm{L}$. & Fabaceae & Tamarindo & Exótica & 54 \\
\hline Spondias tuberosa Arr. Cam. & Anacardiaceae & Umbuzeiro & Nativa & 1 \\
\hline
\end{tabular}




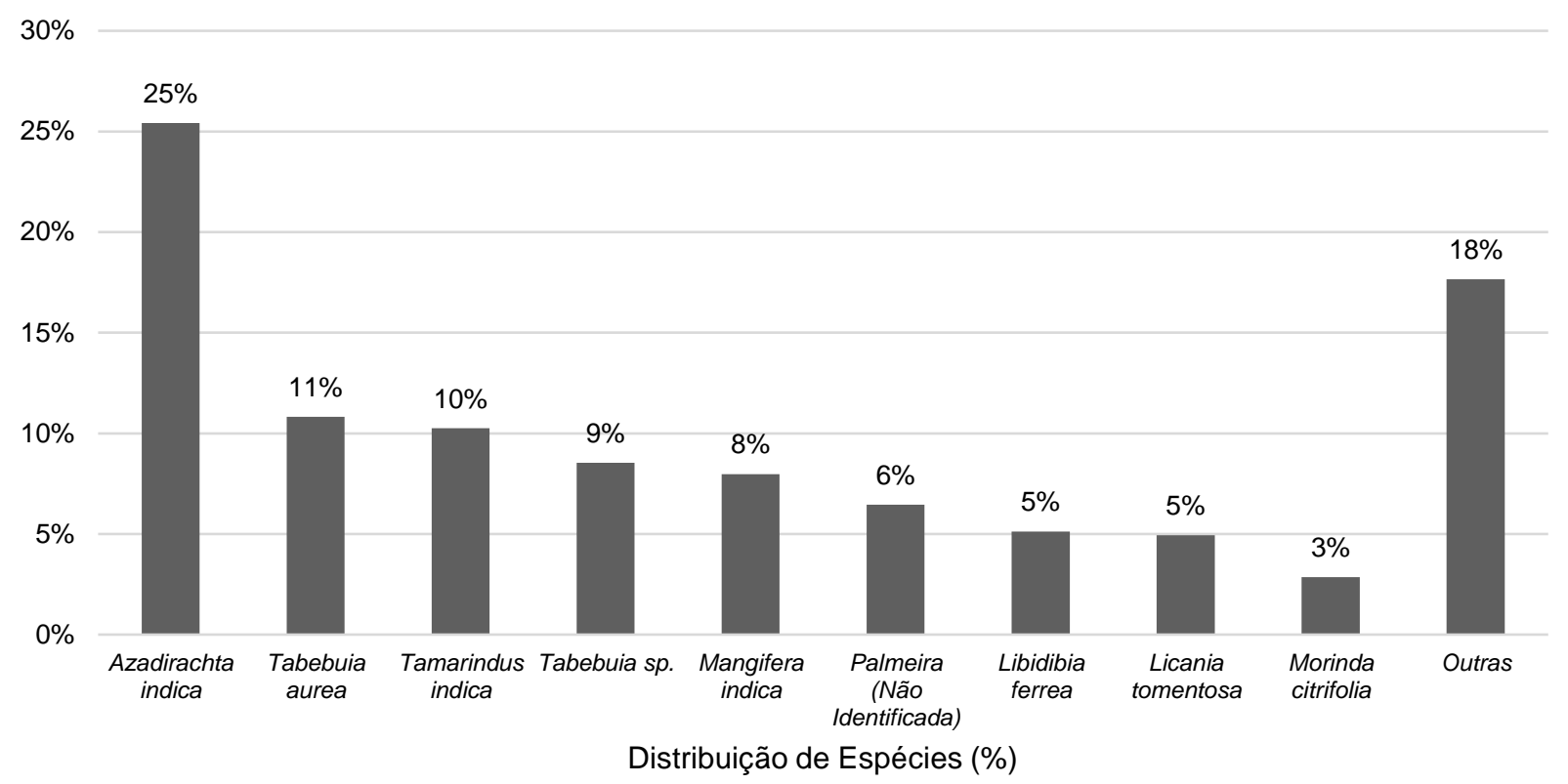

Figura 2. Distribuição percentual das espécies predominantes que compõem a arborização urbana do Campus Sede da UFERSA, Mossoró-RN

Figure 2. Percentage distribution of the predominant species that compose the urban afforestation of the main campus of UFERSA, Mossoró-RN

Observando a distribuição percentual das espécies predominantes que compõem a arborização urbana da universidade (Figura 2), pode-se inferir que nove espécies apresentaram expressividade numérica de indivíduos em relação ao restante (82\%), o que caracteriza uma grande uniformidade na disposição das espécies ao longo das principais ruas do campus. Característica semelhante a encontrada por Gomes et al. (2017), em que foi observada uma concentração de 89,81\% dos indivíduos entre 10 espécies.

Azadirachta indica apresentou $25 \%$ da quantidade total dos indivíduos, valor caracterizado pela sua popular utilização na arborização urbana da região semiárida, principalmente devido às suas características de rápido crescimento e adaptação às condições edafoclimáticas da região (BEZERRA; CASTRO; BOTREL, 2017). Porém, esta quantidade ultrapassa a recomendação de Paiva e Gonçalves (2002), que propõem uma quantidade de até $15 \%$ de indivíduos de uma mesma espécie para um adequado planejamento da arborização urbana. Estes valores recomendados proporcionam a utilização de um número proporcional de espécies, tanto por razões estéticas como fitossanitárias. Sendo assim, valores superiores ao recomendado podem ocasionar riscos à longevidade das espécies, por meio de uma possível queda populacional devido ao ataque de pragas e doenças.

As espécies de origem exótica apresentaram uma maior porcentagem de indivíduos $(62,24 \%)$, quando comparada às espécies de origem nativa (37,76\%). Resultados semelhantes foram encontrados por Leal, Pedrosa-Macêdo e Biondi (2009), ao constatar que 62,36\% das 
espécies avaliadas no Centro Politécnico da Universidade Federal do Paraná eram de origem exótica. Assim como nos trabalhos desenvolvidos por Macêdo, Lisboa e Carvalho (2012), analisando a arborização do Campus Central da Universidade Federal do Rio Grande do Norte, e por Brianezi et al. (2013), avaliando a arborização do Campus Sede da Universidade Federal de Viçosa, em que a quantidade de espécies exóticas representaram a maioria, 50,50\% e $58,26 \%$, respectivamente. Podendo, ainda, ser comparado aos estudos dos autores Redin et al. (2010) e Freitas, Pinheiro e Abrahão (2015), em análises da arborização de praças, nos quais foram observados valores de aos $58 \%$ e $42,8 \%$, respectivamente. Desses $62,24 \%$ de indivíduos de espécies exóticas, 35,68\% são Tamarindus indica e Azadirachta indica. O grande número desses indivíduos é devido, respectivamente, ao mau planejamento da implantação da arborização do campus e, mais recentemente, também atribuído ao modismo.

Referindo-se ao porte da planta, a maioria dos indivíduos foram classificados entre pequeno a médio porte, sendo contabilizadas apenas 17 espécies com grande porte. As alturas médias obtidas foram de 2,66 m, 6,59 m e 12,35 m, para pequeno, médio e grande porte, respectivamente (Figura $3-\mathrm{A}$ ).

Quanto aos resultados obtidos para as medições de circunferência a $50 \mathrm{~cm}$ de altura do solo, foi possível observar que: $27,51 \%$ dos indivíduos apresentaram valor menor que $15 \mathrm{~cm}$, obtendo uma média de $8,70 \mathrm{~cm} ; 34,35 \%$ entre 15,01 e 50,00 cm, obtendo uma média de 30,04 cm; e 38,14\% maior que 50,00 cm, obtendo uma média de 110,20 cm.
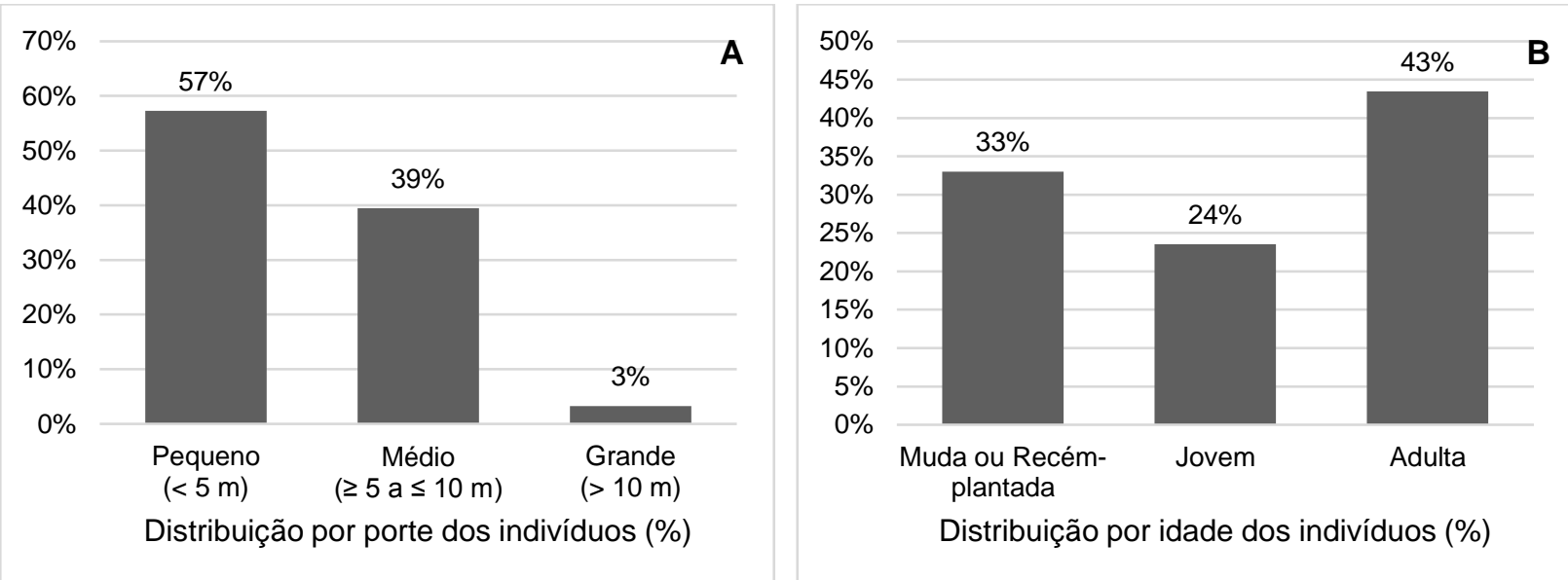

Figura 3. Aspectos da arborização urbana do Campus Sede da UFERSA, Mossoró-RN, quanto ao porte (A) e idade (B) dos indivíduos

Figure 3. Aspects of the urban afforestation of the main campus of UFERSA, Mossoró-RN, regarding the size $(A)$ and age $(B)$ of the individuals

Quanto à idade, foram observados que 33\% dos indivíduos foram classificados como mudas ou recém-plantados, $24 \%$ dos indivíduos como jovens e $43 \%$ dos indivíduos como adultos (Figura 3 -B). Resultados semelhantes foram apresentados por Redin et al. (2010), em avaliação 
da arborização de cinco praças no município de Cachoeira do Sul-RS, e por Toscan et al. (2010), em avaliação da arborização do Bairro Vila Yolanda, do município de Foz do Iguaçu-PR.

No que se refere ao estado geral, 50,47\% dos indivíduos foram classificados como bom, $25,05 \%$ como ótimo, $18,79 \%$ como regular, $5,12 \%$ como ruim e $0,57 \%$ como mortas. Observando o estado fitossanitário das espécies que foram classificadas com estado geral ruim, foi constatado que as mesmas apresentavam intenso ataque por pragas, organismos patogênicos e/ou presença de injurias. Resultados similares foram encontrados pelos autores Brianezi et al. (2013), onde ao avaliarem a arborização do Campus Sede da Universidade Federal de Viçosa, constataram que 57,38\% apresentaram estado ótimo ou bom e apenas 4,01\% apresentaram estado fitossanitário ruim, constatados através de doenças ou injúrias severas. Ainda observando a literatura, os autores Andreatta et al. (2011), verificaram em seus estudos, observando a arborização no contexto urbano de avenidas de Santa Maria-RS, que somente $10 \%$ dos indivíduos analisados apresentavam ótimo estado fitossanitário, estados bom e regular apresentaram $38 \%$ cada e estado ruim apresentou $14 \%$. A presença de indivíduos em estado ruim e morto, encontrados a partir da realização deste trabalho, pode ser atribuída as intervenções de poda irregular e ações de intemperismo, sendo sugerido a remoção e substituição destes indivíduos.

Por fim, foram analisados o entorno e possíveis interferências aos indivíduos arbóreos. Segundo Gonçalves e Paiva (2013), as árvores plantadas no ambiente urbano, necessitam de que suas raízes sejam protegidas, levando em consideração o local de plantio. Esta proteção às raízes deve ser mais efetiva em locais que apresentam solo com impermeabilidade, como é o caso das ruas e dos estacionamentos. A área livre disponível e a situação do calçamento ao redor dos indivíduos são apresentadas na figura 4.
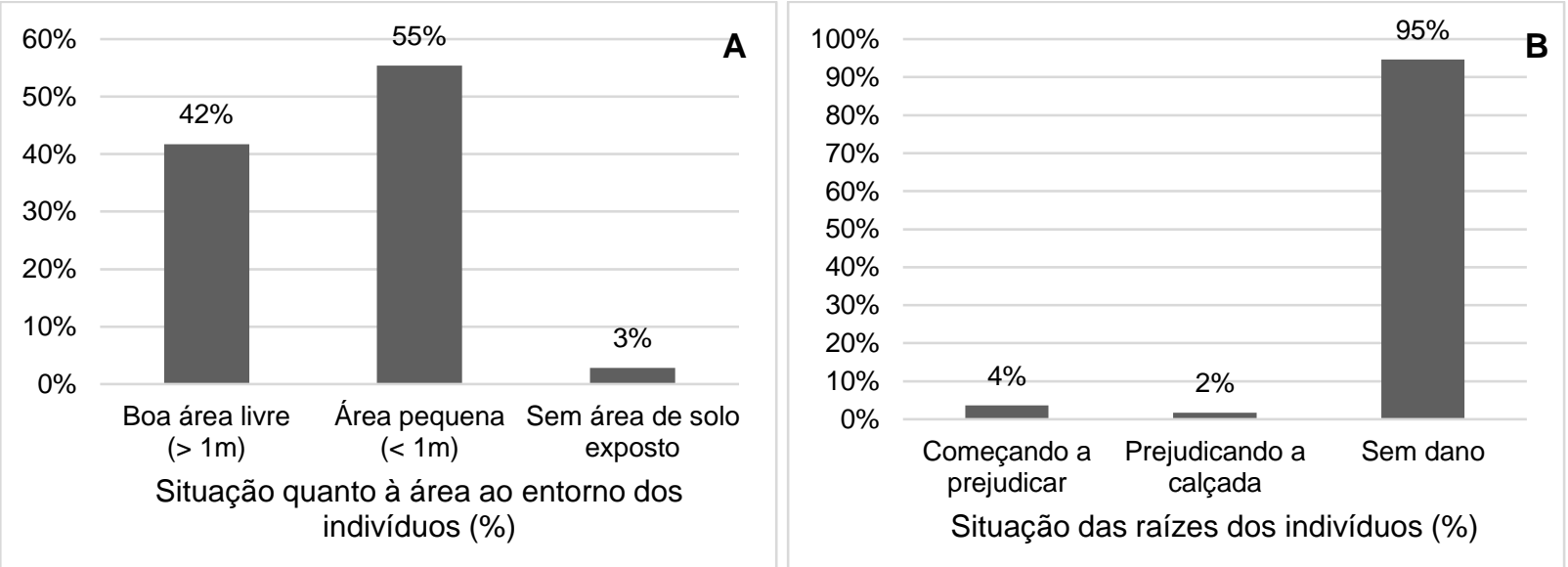

Figura 4. Aspectos do entorno da arborização urbana do Campus Sede da UFERSA, Mossoró-RN, quanto à área livre $(A)$ e situação das raízes $(B)$ dos indivíduos

Figure 4. Aspects of the urban afforestation environment of the main campus UFERSA headquarters, Mossoró-RN, regarding the free área $(A)$ and the situation of the roots $(B)$ of the individuals 
Cerca de $55 \%$ dos indivíduos estavam localizados em uma área considerada como pequena, enquanto que $42 \%$ dos indivíduos apresentaram uma área livre adequada. Contudo, $3 \%$ dos indivíduos não apresentaram área de solo exposto (Figura 4 - A). Toscan et al. (2010), a partir de inventário e análise da arborização urbana no município de Foz do Iguaçu-PR, observaram que $56,86 \%$ possuíam boa área livre de solo, 32,82\% apresentaram uma pequena área de solo exposto, e 10,61\% não apresentaram área de solo exposto.

A ausência de um espaço adequado para o desenvolvimento e disposição das raízes, advindo do mal planejamento da arborização, ocasionam problemas como rachaduras e quebras no calçamento e vias ao redor, como também danos às raízes das plantas (REDIN et al., 2010). Esse fator pôde ser observado a partir da avaliação da situação da raiz, onde foi constatado que $95 \%$ dos indivíduos não apresentavam danos à estrutura das vias ou calçadas, $4 \%$ apresentavam danos iniciais, e apenas $2 \%$ estavam prejudicando severamente a estrutura das vias ou calçadas (Figura 4 - B). Valores apresentados por Toscan et al. (2010), levando em consideração a situação da raiz, evidenciam que 63,10\% dos indivíduos não apresentavam danos, 31,74\% estavam começando a danificar a estrutura, e 5,16\% dos indivíduos estavam prejudicando a calçada.

Outro aspecto também avaliado foi à presença de fiação elétrica logo acima da copa das árvores, onde grande maioria das árvores, 79,13\% dos indivíduos, apresentou fiação ausente acima de suas copas. A baixa frequência de indivíduos com copas em conflito com a fiação elétrica também foi observada pelos autores Maranho e Paula (2014), que encontraram uma frequência de $8,80 \%$ de indivíduos em conflito com a fiação elétrica, a partir da avaliação da diversidade vegetal da arborização que compunha o campus da Universidade Federal do Acre.

A inadequada escolha de espécies e sua distribuição sem um prévio estudo sobre as características físicas da área, podem ocasionar no contato da vegetação com a rede de distribuição elétrica, resultando em perdas e desligamentos. Assim, faz-se necessária a compreensão do comportamento das espécies em todas as suas fases de desenvolvimento, proporcionando uma minimização de interferências futuras (OLIVEIRA et al., 2014).

Quanto à poda da copa, apenas uma pequena parcela de indivíduos, 5,69\%, apresentaram poda de condução, grande maioria não apresentava poda recente ou não tinham sido podados, 55,03\% e 39,28\%, respectivamente. Apesar de grande parte dos indivíduos não apresentarem podas recentes, foi observado a necessidade da reformulação das práticas de poda, visto que as ações inadequadas destas, geralmente do tipo poda drástica, ocasionaram lesões nas árvores, dando um aspecto desconforme ao visto naturalmente. 


\section{CONCLUSÕES}

O campus sede da UFERSA apresenta uma grande quantidade de indivíduos arbóreos, porém foi observado uma baixa heterogeneidade destes, visto que grande parte dos indivíduos encontrados se concentram em poucas espécies. Dentre essas espécies, há uma predominância de exóticas, as quais podem competir com as espécies nativas ali encontradas, ocasionando prejuízos ao ecossistema.

Os resultados obtidos refletem a necessidade de um planejamento da arborização do campus pela administração da universidade, em que se considere a escolha correta de espécies para cada local, proporcionando a adequada distribuição de espécies, como também o manejo de espécies em estado fitossanitário ruim ou mortas. Além disso, a substituição gradual de espécies exóticas por espécies nativas, favoreceriam a biodiversidade local em longo prazo.

\section{REFERÊNCIAS}

ALVAREZ, I. A.; KILL, L. H. P. Arborização, floricultura e paisagismo com plantas da Caatinga. Informativo ABRATES, Londrina, v. 24, n. 3, p. 63-67, 2014.

ANDREATTA, T. R.; BACKES, F. A. A. L.; BELLÉ, R. A.; NEUHAUS, M.; GIRARDI, L. B.; SCHWAB, N. T.; BRANDÃO, B. S. Análise da arborização no contexto urbano de avenidas de Santa Maria, RS. Revista da Sociedade Brasileira de Arborização Urbana, Piracicaba, v. 6, n. 1, p. 36-50, 2011.

BEZERRA, M. B. S.; CASTRO, V. G.; BOTREL, R. T. Arborização da avenida Jerônimo Rosado no município de Baraúna-RN, Brasil. Revista da Sociedade Brasileira de Arborização Urbana, Piracicaba, v. 12, n. 1, p. 122-131, 2017.

BRIANEZI, D.; JACOVINE, L. A. G.; GONÇALVES, W.; ROCHA, S. J. S. S. da. Avaliação da arborização no campus-sede da Universidade Federal de Viçosa. Revista da Sociedade Brasileira de Arborização Urbana, Piracicaba, v. 8, n. 4, p. 89-106, 2013.

DIAS, P. M. S.; DIODATO, M. A.; GRIGIO, A. M. Levantamento fitossociológico de remanescentes florestais do município de Mossoró-RN. Revista Caatinga, Mossoró, v. 27, n. 4, p. 183-190, 2014.

FREITAS, W. K. de; PINHEIRO, M. A. S.; ABRAHAO, L. L. F. Análise da Arborização de quatro praças no Bairro da Tijuca, RJ, Brasil. Revista Floresta e Ambiente, Rio de Janeiro, v. 22, n. 1, p. 23-31, 2015.

GARIGLIO, M. A.; SAMPAIO, E. V. S. B.; CESTARO, L. A.; KAGEYAMA, P. Uso Sustentável e Conservação dos Recursos Florestais da Caatinga. Brasília, DF: Serviço Florestal Brasileiro, 2010. 368p.

GOMES, S. H. M.; FERREIRA, R. A.; MELLO, A. A. de; SANTOS, L. R. dos; SANTANA, N. A.; GONÇALVES, F. B.; SANTOS, L. R. da C. A vegetação do campus da Universidade Federal de Sergipe: florística e fitossociologia. Revista da Sociedade Brasileira de Arborização Urbana, Piracicaba, v. 12, n. 4, p. 23-41, 2017. 
GONÇALVES, W.; PAIVA, H. N. Implantação da Arborização Urbana: especificações técnicas. Viçosa, MG: UFV, 2013. 53p.

LEAL, L.; PEDROSA-MACEDO, J. H.; BIONDI, D. Censo da arborização do Campus III - Centro Politécnico da Universidade Federal do Paraná. Revista Scientia Agraria, Curitiba, v. 10, n. 6, p. 443-453, 2009.

MACÊDO, B. R. M. de.; LISBOA, C. M. C. A.; CARVALHO, F. G. de. Diagnóstico e diretrizes para a arborização do campus central da Universidade Federal do Rio Grande do Norte. Revista da Sociedade Brasileira de Arborização Urbana, Piracicaba, v. 7, n. 1, p. 35-51, 2012.

MARANHO, A. S.; PAULA, S. R. P. de. Diversidade em uma área verde urbana: avaliação qualitativa da arborização do campus da Universidade Federal do Acre, Brasil. Revista Agroambiente, v. 8, n. 3, p. 404-415, 2014.

OLIVEIRA, A. F. de.; PEREIRA, J. A. A.; COELHO, S. J.; PEREIRA, G. de A. Arborização viária conflituosa com a rede elétrica na região oeste de Belo Horizonte-MG. Revista da Sociedade Brasileira de Arborização Urbana, Piracicaba, v. 11, n. 2, p. 27-44, 2016.

PAIVA, H. N.; GONÇALVES, W. Florestas urbanas: planejamento para melhoria da qualidade de vida. Viçosa, MG: Aprenda Fácil, 2002. 180 p.

PAIVA, H. N. de; VITAL, B. R. Escolha da Espécie Florestal. Viçosa, MG: UFV, 2003. 42p.

REDIN, C. G.; VOGEL, C.; TROJAHN, C. D. P.; GRACIOLI, C. R.; LONGHI, S. J. Análise da arborização urbana em cinco praças do município de Cachoeira do Sul, RS. Revista da Sociedade Brasileira de Arborização Urbana, Piracicaba, v. 5, n. 3, p. 149-164, 2010.

ROCHA, R. T. da; LELES, P. S. dos S.; OLIVEIRA NETO, S. N. de. Arborização de vias públicas em Nova Iguaçu, RJ: o caso dos bairros Rancho Novo e Centro. Revista Árvore, Viçosa, v. 28, n. 4, p. 599-607, 2004.

SANTOS, P. C. da S.; ALVES, L. L. B.; AQUINO, G. S. M.; ALMEIDA, G. N. de; BOTREL, R. T.; CASTRO, V. G. de. Análise da arborização do Parque Municipal Maurício de Oliveira, Mossoró/RN. Revista da Sociedade Brasileira de Arborização Urbana, Piracicaba, v. 12, n. 3, p. 94-106, 2017.

SILVA FILHO, D. F. da; PIZETTA, P. U. C.; ALMEIDA, J. B. S. A.; PIVETTA, K. F. L.; FERRAUDO, A. S. Banco de dados relacional para cadastro, avaliação e manejo da arborização em vias públicas. Revista Árvore, Viçosa, v. 26, n. 5, p. 629-642, 2002.

SILVA, S. A. de O. Análise das variáveis meteorológicas no município de Mossoró-RN (1970-2013). 2014. 46 f. Monografia (Graduação em Agronomia) - Universidade Federal Rural do Semi-Árido, Mossoró, RN, 2014.

TOSCAN, M. A. G.; RICKLI, H. C.; BARTINICK, D.; SANTOS, D. S. dos; ROSSA, D. Inventário e análise da arborização do bairro Vila Yolanda, do município de Foz do Iguaçu-PR. Revista da Sociedade Brasileira de Arborização Urbana, Piracicaba, v. 5, n. 3, p. 165-184, 2010. 